\title{
A subtest analysis of The Montreal Cognitive Assessment (MoCA): which subtests can best discriminate between healthy controls, mild cognitive impairment and Alzheimer's disease?
}

\author{
Juliana Francisco Cecato, José Eduardo Martinelli, Rafael Izbicki, \\ Mônica Sanches Yassuda and Ivan Aprahamian
}

http://dx.doi.org/10.1017/S1041610215001982, Published online by Cambridge University Press 01 December 2015

The authors would like to apologise for a typographical error in the discussion of the above mentioned article.

In the discussion on page 830 of the article, paragraph 'In the present sample, when we tested the accuracy of the MoCA to discriminate between MCI and healthy participants using ROC curves, the best cut-off score was 24 points, with good sensitivity and specificity $(92 \%$ and $82 \%$, respectively).'

Should read:

In the present sample, when we tested the accuracy of the MoCA to discriminate between MCI and healthy participants using ROC curves, the best cut-off score was 24 points, with good sensitivity and specificity ( $83 \%$ and $89 \%$, respectively).

\section{Reference}

Cecato, J.F., Martinelli, J.E., Izbicki, R., Yassuda, M.S. and Aprahamian, I. (2016) 'A subtest analysis of the Montreal cognitive assessment (MoCA): which subtests can best discriminate between healthy controls, mild cognitive impairment and Alzheimer's disease?', International Psychogeriatrics, 28(5), pp. 825-832. doi: 10.1017/S1041610215001982 